\title{
Reductive One-Carbon Homologation of Aldehydes and Ketones
}

\author{
Hélène Lebel* and Chehla Ladjel \\ Département de chimie, Université de Montréal, Montréal, Québec, Canada, H3C 3J7 \\ Supporting Information
}

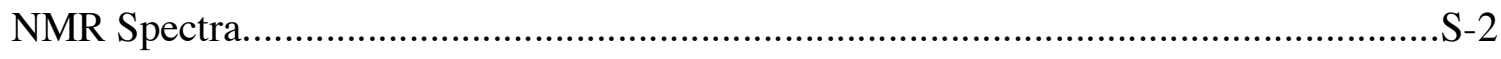




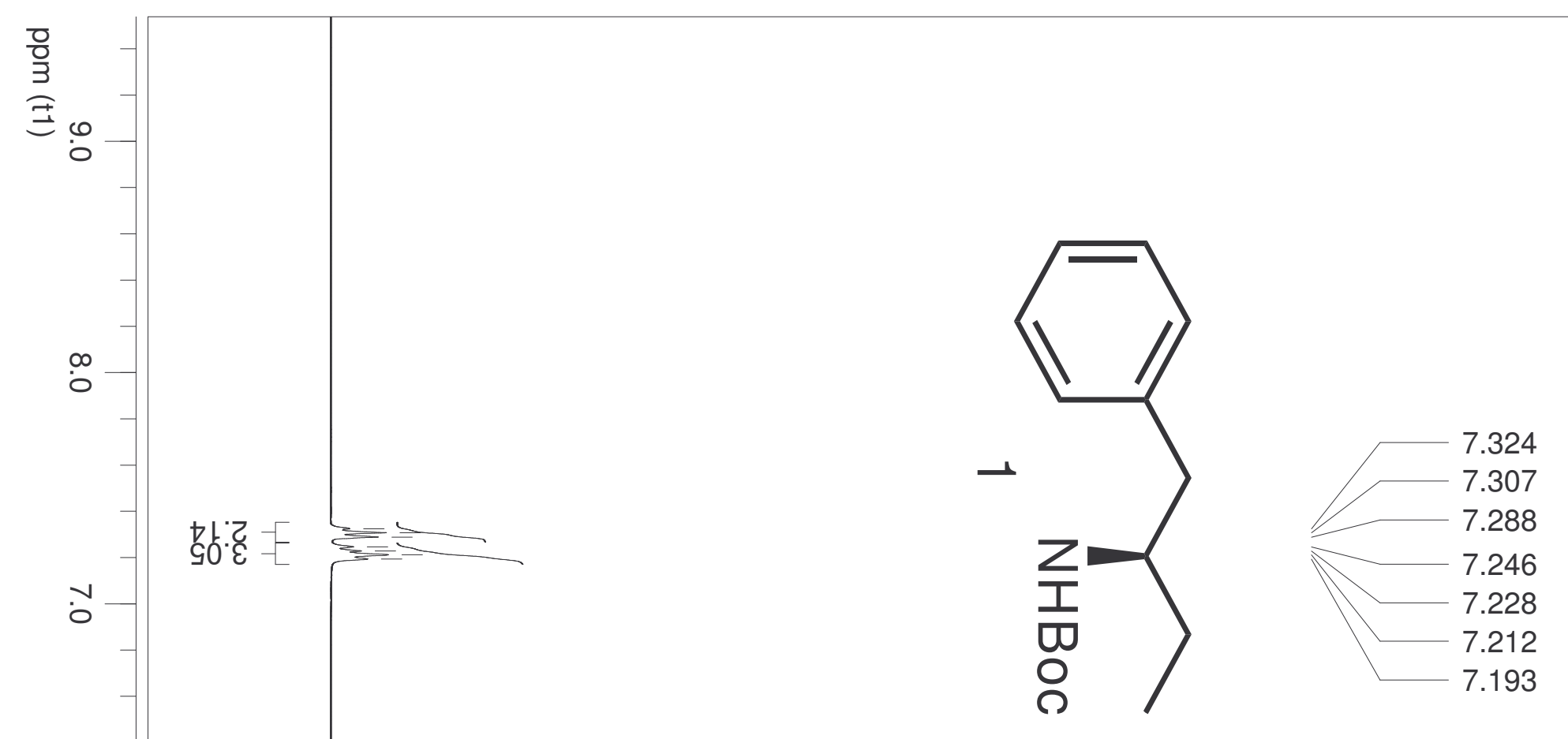

9

G

0

$-\sqrt{0}-\int 80^{\circ}-[\}$

$-\sqrt{0}-18 \cdot 0-[\}-$
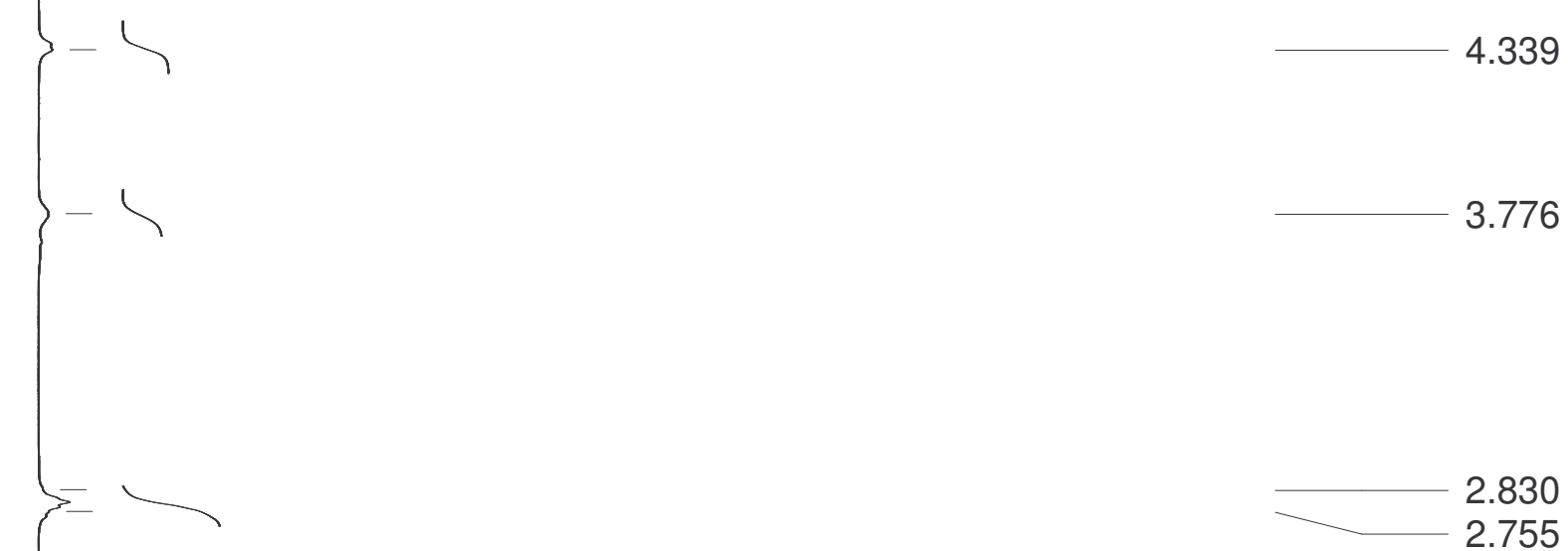

0

$\forall L^{\circ} 0-$

2.755

ñ
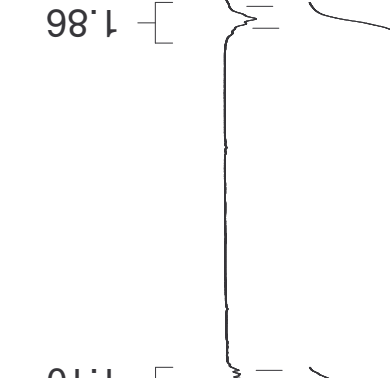

$01:-$
$10.6-$

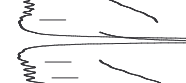

1.588

1.504

1.361 


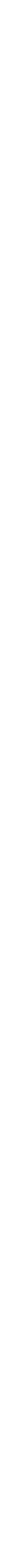




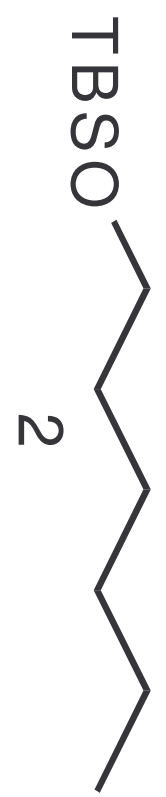



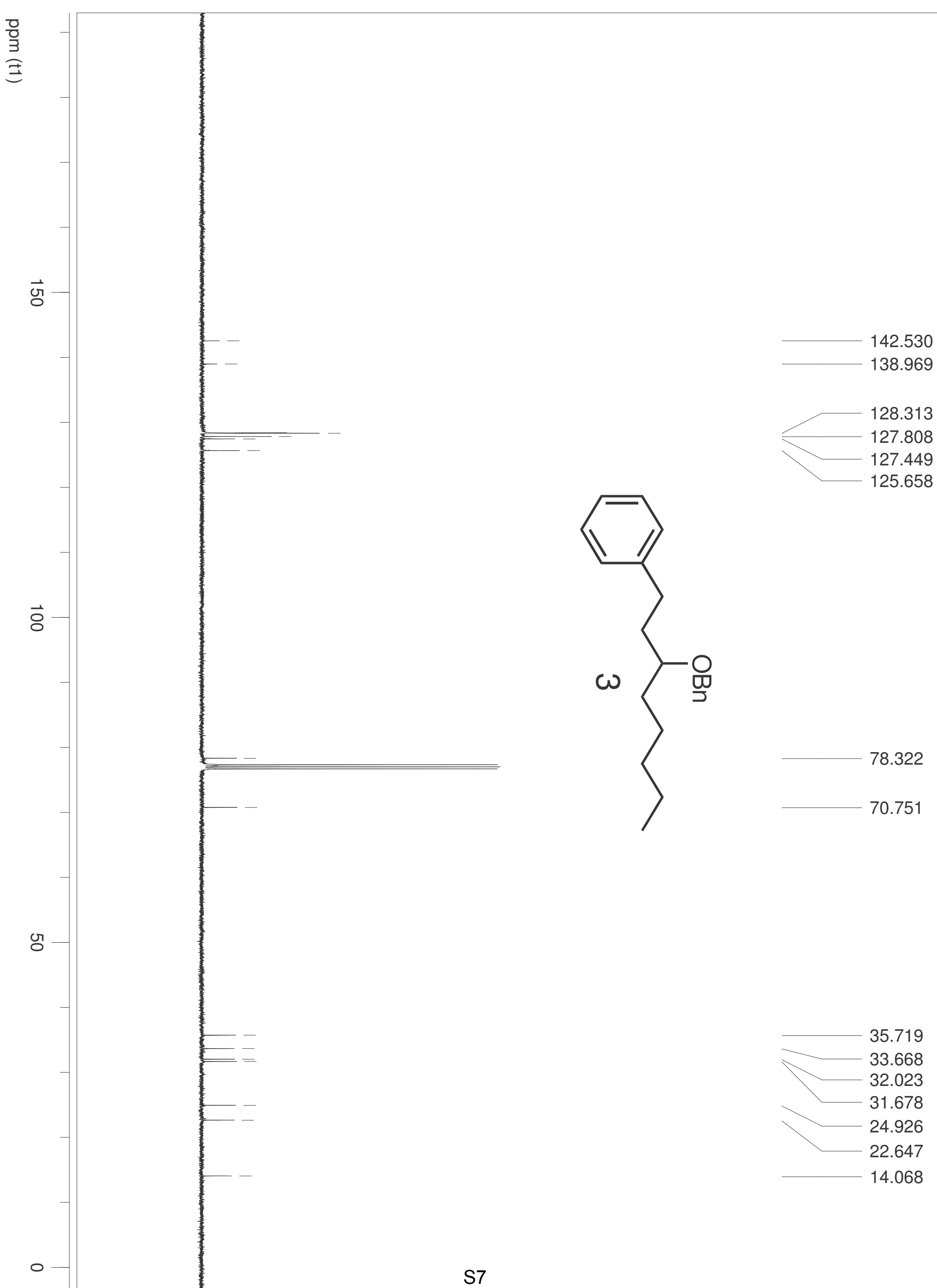

35.719

33.668

32.023

31.678

24.926

22.647

14.068 


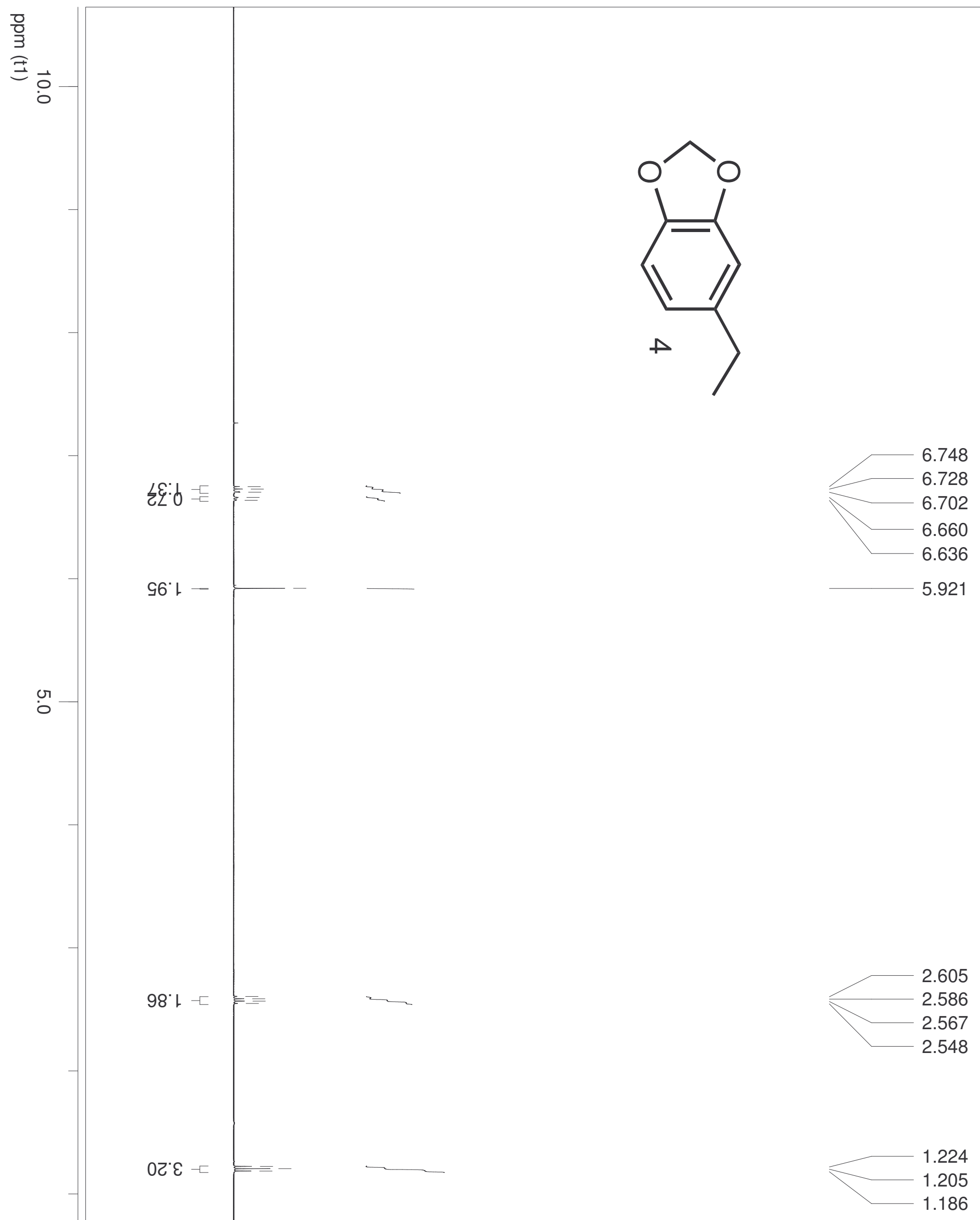

0 
20. - $20^{\circ}+$

$=$

60: $-\square$ $\varepsilon \mathrm{c}^{\circ} 6$ 8ใ: $16^{\circ} \mathrm{C}=$

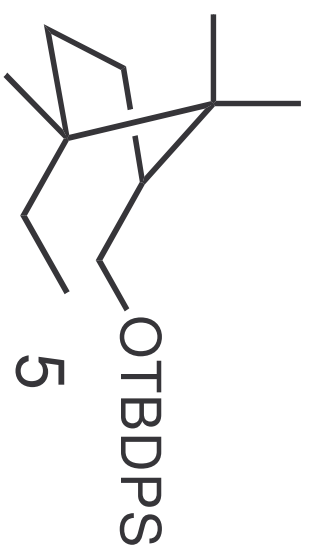

3.717

3.706

3.700

3.689 3.557 3.545 3.540 3.528 2.191 2.176 2.164 2.136 1.847 1.780 1.482 1.430 1.380 1.336 1.292 1.180 1.043 0.862 0.845 0.832 0.819 0.663 


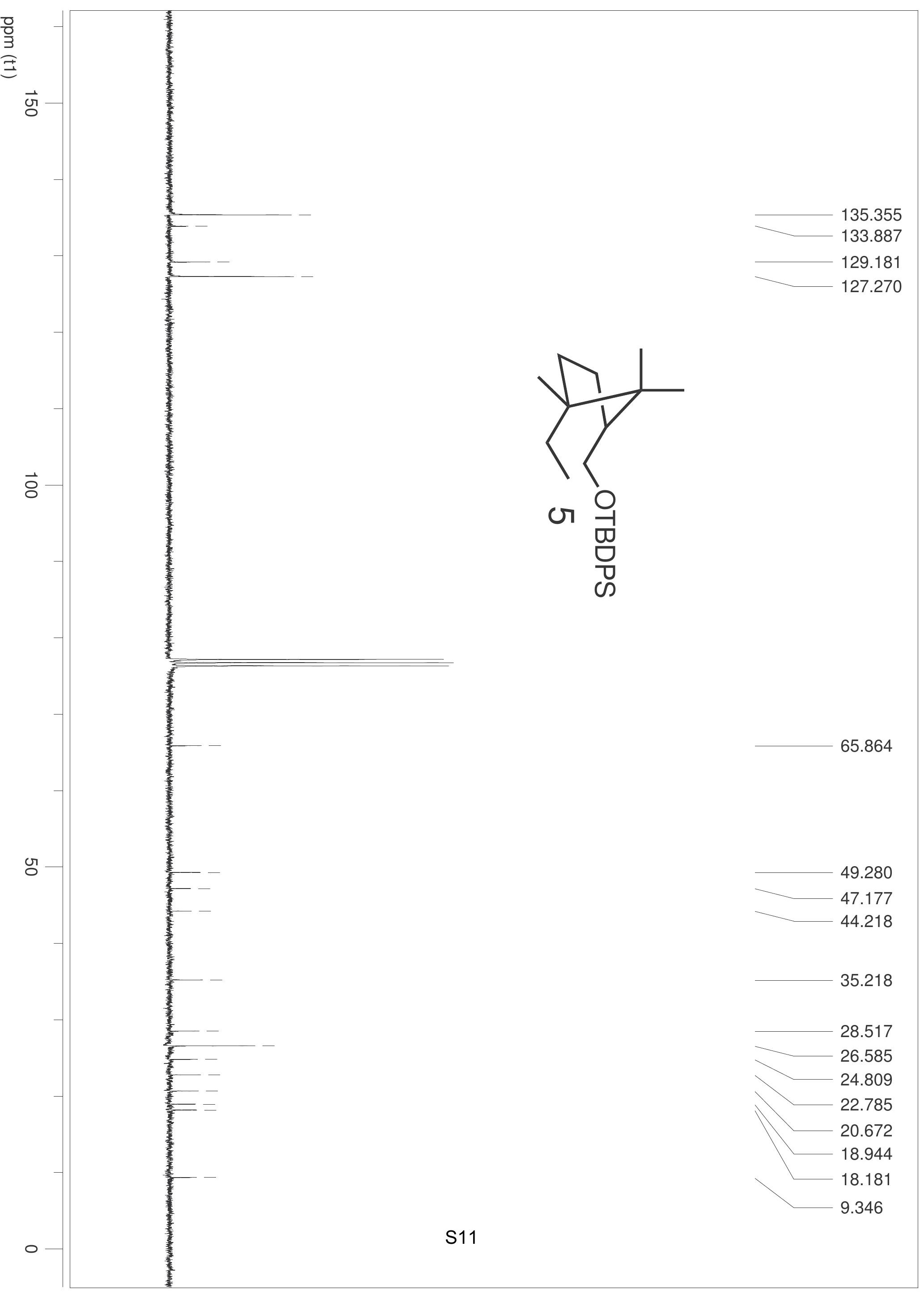



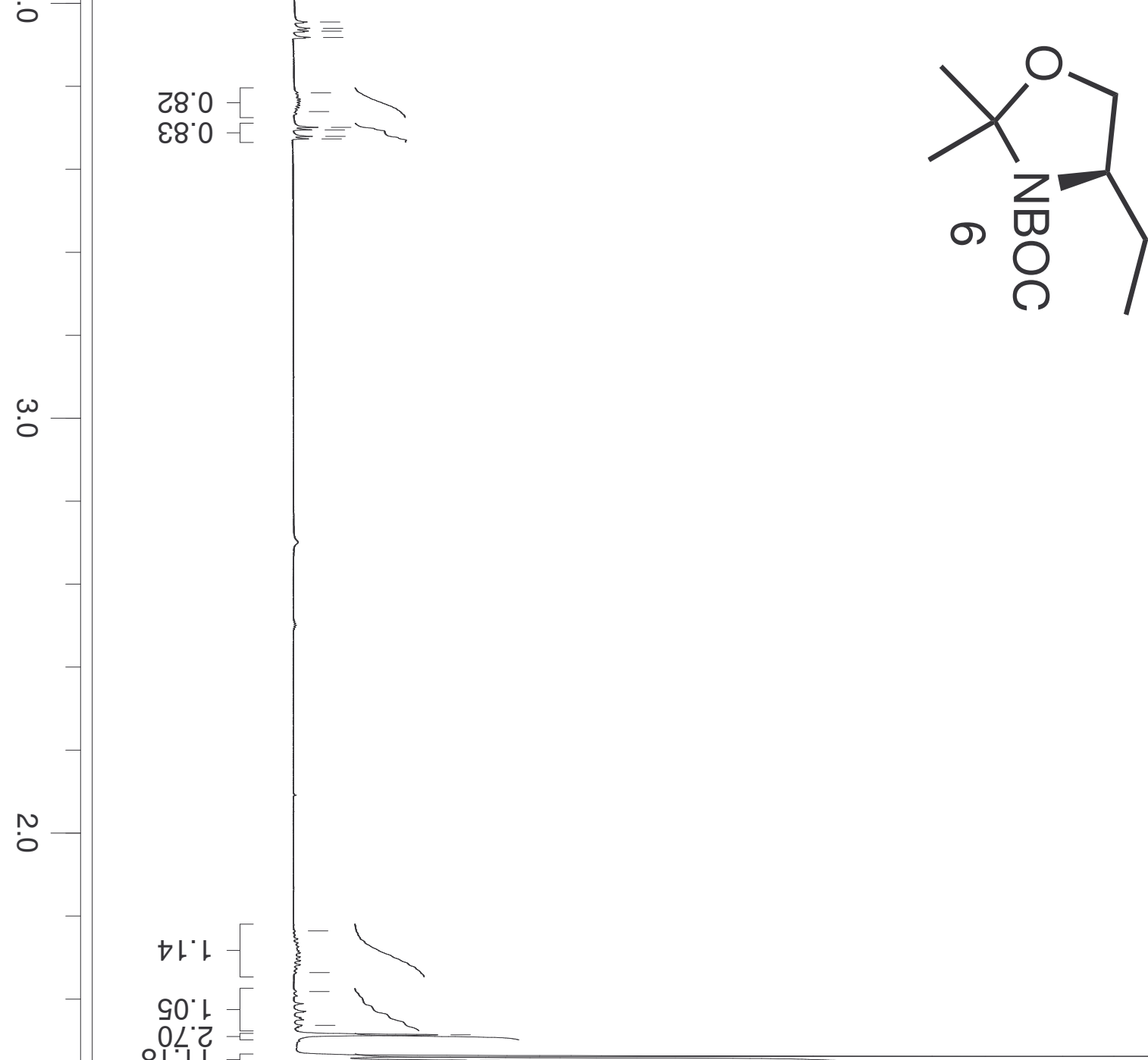


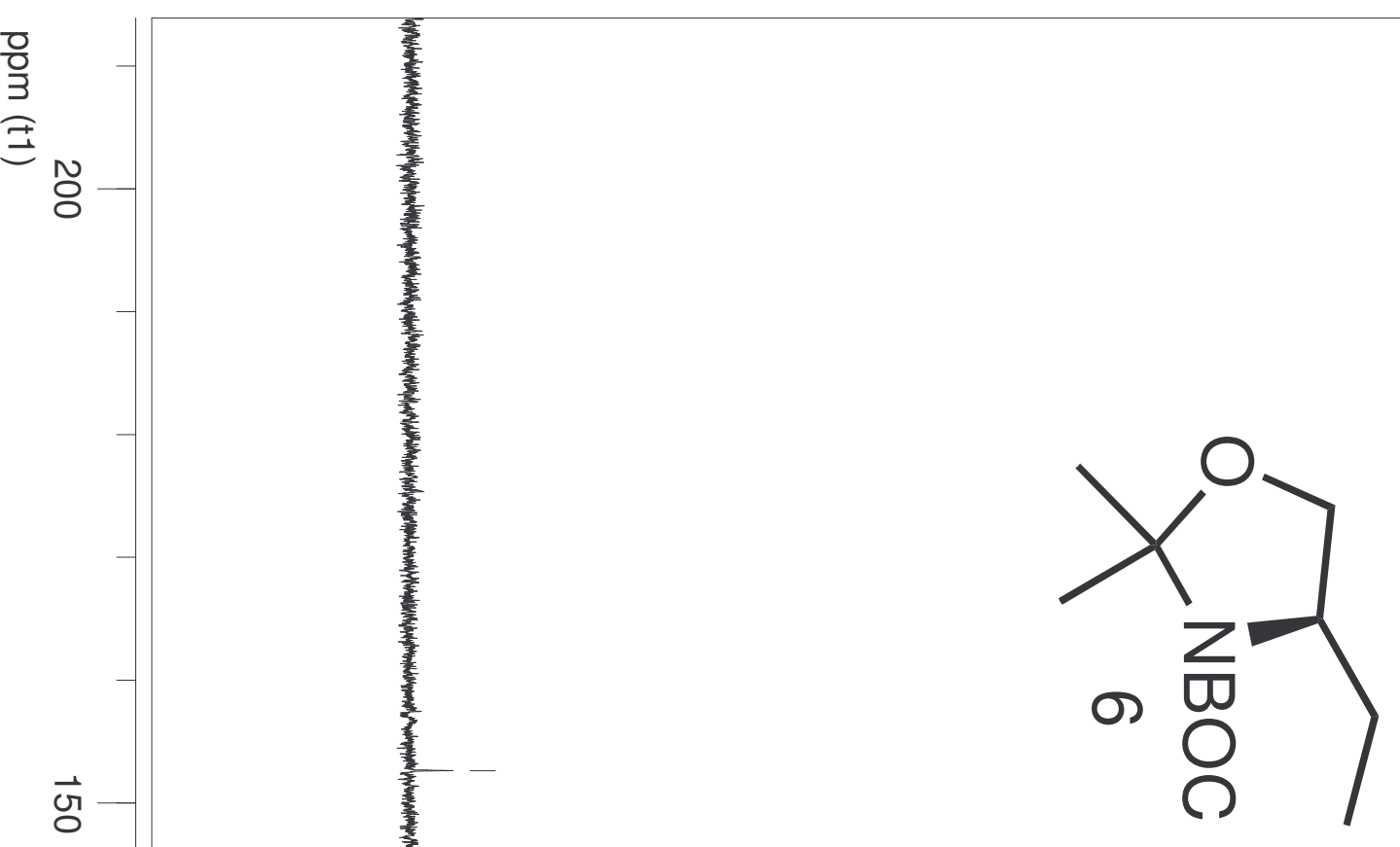


